\title{
Abnormality of Circulatory Reflex and Aldosterone Response during Head-up Tilting in Patients with Primary Aldosteronism
}

\author{
Shin Suzukr, M.D.,* Yutaka Doi, M.D., Tatsuo Shinagawa, M.D., \\ Wataru Aor, M.D., and Kunitake Hasmiba, M.D.
}

\begin{abstract}
Summary
Abnormality of the circulatory reflexes has been reported in patients with primary aldosteronism. However, changes in blood pressure, heart rate, plasma renin activity (PRA), and plasma aldosterone concentration (PAG) after head-up tilting in primary aldosteronism have not yet been reported. Seven patients with primary aldosteronism were tilted to a 65 degree head-up position which was maintained for $30 \mathrm{~min}$. Systolic blood pressure decreased significantly $5 \mathrm{~min}$ after tilting and remained at this level during the period of tilting. Diastolic blood pressure did not change during the tilting. Heart rate increased after $5 \mathrm{~min}$ of tilting and this level of heart rate was maintained for $30 \mathrm{~min}$. Plasma renin activity was low and did not change during tilting. However, plasma aldosterone concentration increased significantly 20 min after tilting. Plasma cortisol concentration and plasma ACTH concentration also increased significantly. These results suggest that primary aldosteronism causes abnormalities of the circulatory reflexes. The increase of endogenous AGTH may increase plasma aldosterone concentration in patients with primary aldosteronism.
\end{abstract}

\section{Additional Indexing Words:}

Primary aldosteronism

Aldosterone

Tilting Renin

$\Gamma$ HE head-up tilt test has been used to evaluate the mechanism of blood pressure maintenance in patients with hypertension ${ }^{1,2)}$ and in patients with orthostatic hypotension. ${ }^{3)-5}$ Increased plasma norepinephrine, ${ }^{2)-5)}$ increased PRA, ${ }^{6)-10)}$ and increased plasma aldosterone ${ }^{11)}$ were reported during tilting in normal subjects. These factors may represent the mechanisms of

From the Third Department of Internal Medicine, Nagasaki University School of Medicine, 7-1 Sakamoto-machi, Nagasaki 852, Japan.

* To whom reprints should be addressed.

Received for publication August 2, 1985.

Manuscript revised May 31, 1986. 
blood pressure maintenance in response to the decrease in cardiac output during tilting. Increased aldosterone secretion is considered to be caused by a potentiated renin-angiotensin system in this situation. ${ }^{11}$

In primary aldosteronism, it is believed that aldosterone increases sodium reabsorbtion in the renal tubules which increases circulatory plasma volume. PRA is usually suppressed and does not respond to any renin stimulation test in patients with primary aldosteronism. Biglieri et al ${ }^{121}$ reported abnormalities of the circulatory reflexes in primary aldosteronism. They reported that the hypertensive responses and reflex bradycardia to Valsalva's maneuver were minimal or absent in patients with primary aldosteronism. The present study was carried out to evaluate whether there are some abnormalities of the blood pressure controlling mechanism in patients with primary aldosteronism. The effect of the head-up tilt test on aldosterone secretion was also studied in patients with primary aldosteronism.

\section{Materials and Methods}

Seven patients with primary aldosteronism ( 1 male, 6 females, aged

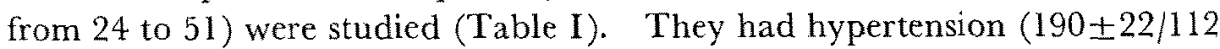
$\pm 14 \mathrm{mmHg})$, hypokalemia $(2.6 \pm 0.4 \mathrm{mEq} / \mathrm{L})$, low PRA $(<0.1 \mathrm{ng} / \mathrm{ml} / \mathrm{hr})$, and high PAC $(>300 \mathrm{pg} / \mathrm{ml})$. Diagnosis of primary aldosteronism was also confirmed retrospectively at surgery in all of these patients. Hypertension and hypopotassemia improved after removal of the aldosteronoma. All subjects were admitted to hospital and all drugs were withheld. A normal sodium diet ( $12 \mathrm{~g} /$ day) was given for more than 7 days. The head-up tilt test was performed after $30 \mathrm{~min}$ supine rest on the table in the morning, the patients having fasted. The table was tilted abruptly to a 65 degree headup position which was maintained for 30 min. Arterial blood pressure was

Table 1. Clinical Findings in 7 Patients with Primary Aldosteronism

\begin{tabular}{|c|c|c|c|c|c|c|c|c|c|c|c|c|}
\hline \multirow{2}{*}{ No. } & \multirow{2}{*}{ Patient } & \multirow{2}{*}{$\begin{array}{l}\text { Age } \\
(\text { yo) }\end{array}$} & \multirow{2}{*}{ Sex } & \multirow{2}{*}{$\begin{array}{l}\text { Blood } \\
\text { Pressure } \\
\text { (mmHg) }\end{array}$} & \multicolumn{3}{|c|}{ Serum $(\mathrm{mEq} / \mathrm{L})$} & \multirow{2}{*}{$\begin{array}{c}\mathrm{K} \\
\text { Clear- } \\
\text { ance } \\
\text { (mll } \\
\text { min) }\end{array}$} & \multirow{2}{*}{$\begin{array}{c}\text { TBK } \\
(\%)\end{array}$} & \multirow{2}{*}{$\begin{array}{l}\text { PRA } \\
(\mathrm{ng} / \\
\mathrm{ml} / \mathrm{hr})\end{array}$} & \multirow{2}{*}{$\begin{array}{l}\mathrm{PAC} \\
(\mathrm{pg} / \mathrm{ml})\end{array}$} & \multirow{2}{*}{$\begin{array}{l}\text { Ade- } \\
\text { noma } \\
\text { Side }\end{array}$} \\
\hline & & & & & $\mathrm{Na}$ & $\mathrm{K}$ & $\mathrm{Gl}$ & & & & & \\
\hline 1 & $\mathrm{TN}$ & 24 & M & $168 / 104$ & 147 & 3.2 & 102 & 32 & 105 & $<0.1$ & 314 & $\mathrm{R}$ \\
\hline 2 & $\mathrm{KS}$ & 28 & $\mathrm{~F}$ & $174 / 110$ & 142 & 2.7 & 106 & 58 & 77 & 0.1 & 311 & $\mathbf{L}$ \\
\hline 3 & FN & 28 & $\mathbf{F}$ & $214 / 138$ & 148 & 2.7 & 100 & 51 & 78 & 0.1 & 660 & $\mathbf{L}$ \\
\hline 4 & MK & 28 & $\mathrm{~F}$ & $218 / 110$ & 141 & 2.1 & 100 & 33 & 72 & 0.1 & 506 & $\mathbf{R}$ \\
\hline 5 & $\mathrm{KM}$ & 30 & $\mathrm{~F}$ & $180 / 106$ & 147 & 2.8 & 102 & 46 & 94 & $<0.1$ & 686 & $L$ \\
\hline 6 & MM & 41 & $\mathrm{~F}$ & $210 / 120$ & 143 & 3.0 & 108 & 48 & $(-)$ & 0.1 & 346 & $\mathrm{~L}$ \\
\hline 7 & SK & 51 & F & $172 / 94$ & 146 & 2.0 & 93 & 33 & 80 & $<0.1$ & 556 & $\mathrm{~L}$ \\
\hline
\end{tabular}



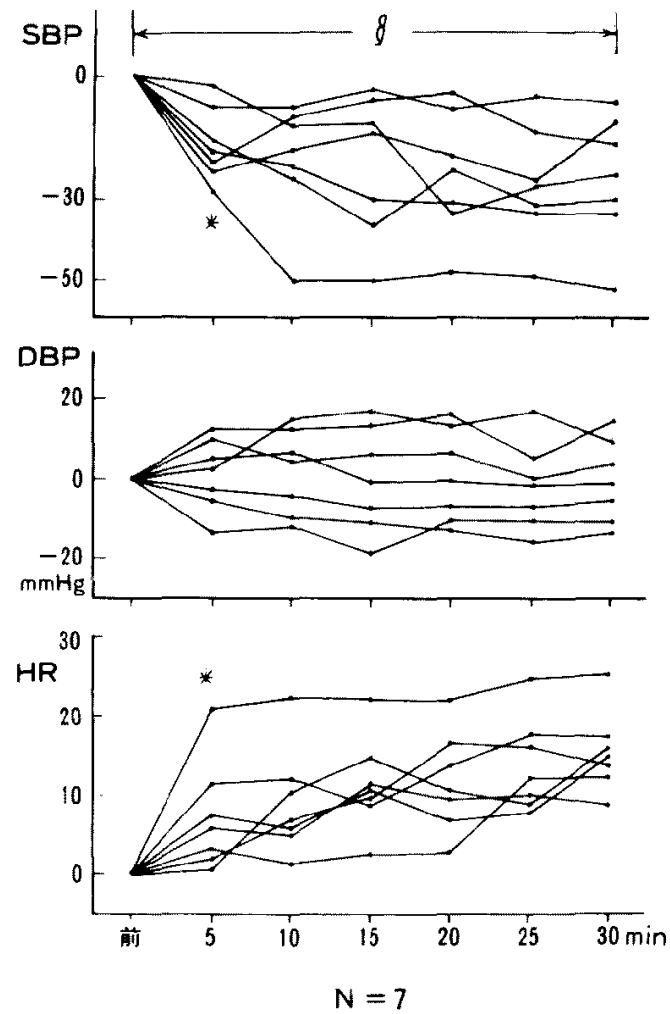

Fig. 1. Changes in systolic blood pressure (SBP), diastolic blood pressure (DBP), and heart rate (HR) during tilting are shown. $\mathrm{N}=7,{ }^{*} \mathrm{p}<0.05$.

measured by sphygmomanometry. Venous blood samples were collected before and during tilting $(0,10,20$, and 30) for the measurement of PRA, plasma aldosterone concentration (PAC), plasma cortisol concentration (PCG), and plasma ACTH concentration (ACTH). PRA was measured by radioimmunoassay using CIS kits. Plasma samples ( $1 \mathrm{ml}$ ) were incubated with $20 \mu \mathrm{l}$ of 8 -hydroxyquinoline sulphate $0.13 \%$ and $6 \mu \mathrm{l}$ of 2,3 dimercaptopropanol. After incubation for 1.5 hours at $37^{\circ} \mathrm{C}$, the samples were transferred to an ice bath, and $50 \mu \mathrm{l}$ aliquots were taken for radioimmunoassay of generated angiotensin I. PAC was measured by radioimmunoassay using CIS kits. One $\mathrm{ml}$ of plasma sample and $4 \mathrm{ml}$ of dichlormethane were mixed and shaken for $10 \mathrm{~min}$ and centrifuged. Two $\mathrm{ml}$ of the dichlormethane layer were obtained and dried using nitrate gas, and the resultant sediment was dissolved in $0.1 \mathrm{ml}$ of phosphate buffer, $\mathrm{pH}$ 7.4. Radioimmunoassay of aldosterone was done using a CIS kit. PCC was measured using an Eiken Immunochemical kit (Osaka, Japan) and ACTH was measured using a 

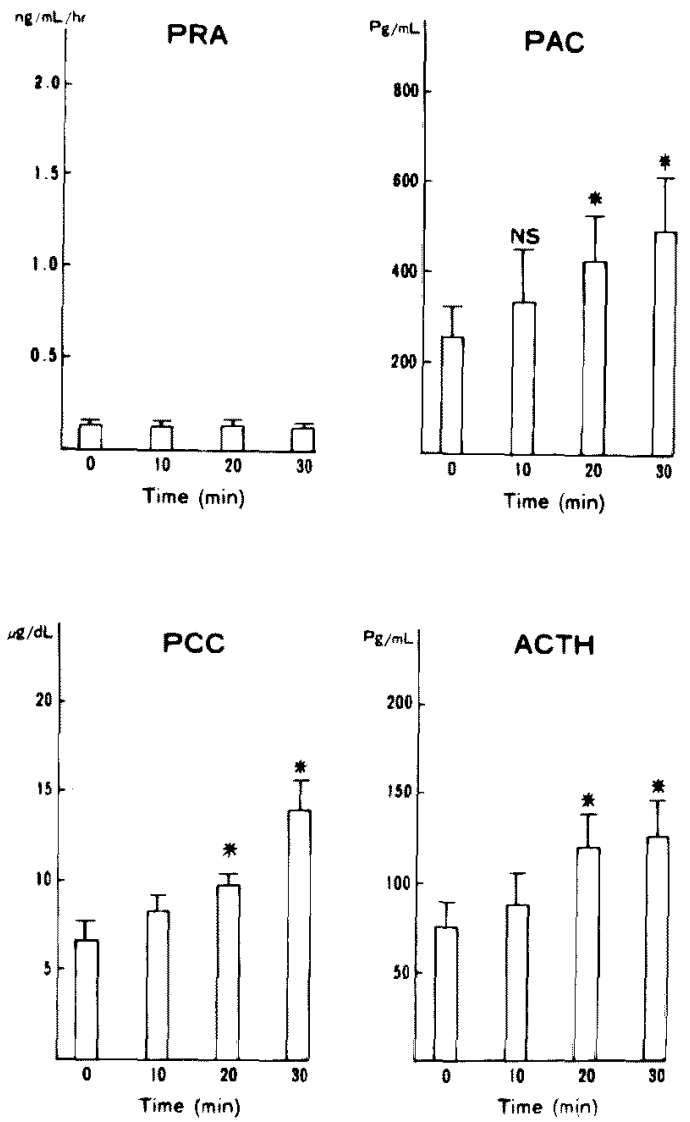

Fig. 2. Changes of PRA, PAC, PCG, and ACTH during tilting are shown. Statistical difference from the control value $(0 \mathrm{~min})$ is given above each column $(\mathrm{N}=7, * \mathrm{p}<0.05, \mathrm{NS}=$ not significant $)$.

CIS kit.

Statistical analysis was performed by the paired t-test with $\log$ transformation. Significance was defined as a $\mathrm{p}$ value of less than 0.05 .

\section{Results}

Fig. 1 shows the changes in systolic blood pressure, diastolic blood pressure, and heart rate during tilting. Systolic blood pressure decreased significantly $5 \mathrm{~min}$ after tilting and this level of systolic blood pressure was maintained for $30 \mathrm{~min}$. Diastolic blood pressure increased more than $5 \mathrm{mmHg}$ during tilting for $30 \mathrm{~min}$. However, changes in diastolic pressure during tilting in these subjects were not significant. Heart rate increased significantly 
$5 \mathrm{~min}$ after tilting and this level of heart rate was maintained for $30 \mathrm{~min}$.

Fig. 2 shows the changes in PRA, PAC, PCC, and ACTH during tilting. PRA was very low and did not change during tilting. PAC, PCC, and ACTH all increased significantly 20,30 , and $20 \mathrm{~min}$ after tilting, respectively.

\section{Discussion}

It has been reported that abnormalities of the circulatory reflexes exist in patients with primary aldosteronism. ${ }^{12)}$ In this report, the circulatory reflex was evaluated using head-up tilting in patients with primary aldosteronism. Our previous repor ${ }^{13)}$ suggested that diastolic blood pressure increased significantly in healthy normal volunteers. Thus, the present study showing that diastolic blood pressure did not increase during tilting in most of our subjects with primary aldosteronism supports the hypothesis that circulatory reflex abnormalities do exist in this population. It was considered that the mechanisms of blood pressure maintenance after tilting were the sympathetic nervous system, ${ }^{2,51,8), 91}$ the renin-angiotensin system, ${ }^{61-101}$ and aldosterone. ${ }^{11}$ However, other factors may contribute to the control of blood pressure after tilting. In primary aldosteronism, it may be possible that the renin-angiotensin system is markedly suppressed and does not contribute to blood pressure regulation. Our results showing that PRA did not increase during tilting in patients with primary aldosteronism indicate that the renin-angiotensin system does not contribute to the maintenance of blood pressure during tilting in patients with this disease. On the other hand, PAC increased during tilting, indicating that this response of aldosterone was not caused by the renin-angiotensin system. Since PCC and ACTH also increased during tilting, this increase of PAC may have been caused by the endogenous increase of ACTH. The possibility that hypokalemia contributed in this abnormality of the circulatory reflex in patients with primary aldosteronism cannot be excluded in this study since hypokalemia was present in all of these subjects and head-up tilting was not performed after surgery.

A recent report ${ }^{14}$ ) suggests that aldosterone secretion in primary aldosteronism is controlled by ACTH since the diurnal variation of PAC in primary aldosteronism is suppressed by dexamethasone administration, and ACTH administration increased PAC in this disease. Furthermore, Nicholls et al $\left.{ }^{15}\right)$ reported that a low dose of ACTH stimulated aldosterone secretion in healthy subjects. Our results, showing that PAC increased during tilting, support these findings.

These results suggest that patients with primary aldosteronism have 
abnormalities of the circulatory reflexes. The increase of endogenous ACTH increases PAC in subjects with primary aldosteronism during tilting.

\section{References}

1. Frohlich ED, Tarazi RC, Ulrych M, Dustan HP, Page IH: Tilt test for investigating a neural component in hypertension. Circulation 36: 387, 1967

2. Hickler RB, Hamlin JT, Wells RE: Plasma norepinephrine response to tilting in essential hypertension. Circulation 20: 422, 1959

3. Allen SC, Taylor GL, Hall VE: A study of orthostatic insufficiency by the tilt-board method. Am J Physiol 143: 11, 1945

4. Love DR, Brown JJ, Chin RH, Johnson RH, Liver AF, Park DM, Robertson JIS: Plasma renin in idiopathic orthostatic hypertension: differential response in subjects with probable afferent and efferent autonomic failure. Clin Sci 41:289, 1971

5. Molzahn M, Dissmann TH, Halim S, Lohmann FW, Oelkers W: Orthostatic changes of haemodynamics, renal function, plasma catecholamines and plasma renin concentration in normal and hypertensive man. Clin Sci 42: 209, 1972

6. Oparil S, Vassaux C, Sanders CA, Haber E: Role of renin in acute postural homeostasis. Circulation 41: 89, 1970

7. Hesse B, Ring-Larsen H, Nielson I, Christensen NJ: Renin stimulation by passive tilting: the influence of an antigravity suit on postural changes in plasma renin activity, plasma noradrenaline concentration and kidney function in normal man. Scand J Clin Lab Invest 38: 163, 1978

8. Stella A, Zanchetti A: Effects of renal denervation on renin release in response to tilting and furosemide. Am J Physiol 232: 500, 1977

9. Cuche JL, Kuchel O, Barbeau A, Boucher R, Genest J: Relationship between the adrenergic nervous system and renin during adaptation to upright posture: a possible role for 3,4 dihydroxy-phenethylamine (dopamine). Clin Sci 43: 481, 1972

10. Brown JJ, Davies DL, Lever AF, Mcpherson D, Robertson JIS: Plasma renin concentration in relation to changes in posture. Clin Sci 30:279, 1966

11. Sancho JRR, Burton J, Barger AC, Haber E: The role of the renin-angiotensin-aldosterone system in cardiovascular homeostasis in normal human subjects. Circulation 53: 400, 1976

12. Biglieri EG, Mcllroy MB: Abnormalities of renal functions and circulatory reflexes in primary aldosteronism. Circulation 33: 78, 1966

13. Suzuki S, Doi Y, Aoi W, Hashiba K: Effect of head-up tilting on blood pressure, heart rate, cardiac output, and renin-angiotensin-aldosterone system in normal subjects. Igaku no Ayumi 117: 433, 1981 (in Japanese)

14. Schambelan M, Brust NR, Chang BCF, Slater KL, Biglieri EG: Circadian rhythm and effect of posture on plasma aldosterone concentration in primary aldosteronism. J Clin Endocrinol Metab 43: 115, 1976

15. Nicholls MG, Espiner EA, Konald RA: Plasma aldosterone response to low dose AGTH stimulation. J Clin Endocrinol Metab 41: 186, 1975 